\title{
Emotional Reactions to Tonal and Noise Components of Environmental Sounds*
}

\author{
Daniel Västfjäll $1^{1,2,3 \#}$ \\ ${ }^{1}$ Department of Applied Acoustics, Chalmers University of Technology, Göteborg, Sweden \\ ${ }^{2}$ Department of Behavioral Sciences and Learning, Linköping University, Linköping, Sweden \\ ${ }^{3}$ Decision Research, Eugene, USA \\ Email: \#daniel.vastfjall@liu.se
}

Received January $21^{\text {st }}, 2013$; revised February $25^{\text {th }}, 2013$; accepted March $22^{\text {nd }}, 2013$

\begin{abstract}
Copyright (C) 2013 Daniel Västfjäll. This is an open access article distributed under the Creative Commons Attribution License, which permits unrestricted use, distribution, and reproduction in any medium, provided the original work is properly cited. In accordance of the Creative Commons Attribution License all Copyrights (C) 2013 are reserved for SCIRP and the owner of the intellectual property Daniel Västfjäll. All Copyright (C 2013 are guarded by law and by SCIRP as a guardian.
\end{abstract}

In the present study, a two-dimensional model of human emotional reactions is used to predict auditory perception. The models' discriminant validity is tested in an experiment where one group of participants use a two-dimensional emotion measure to rate their reactions to sounds systematically varied in tone and noise spectral level content. Another group of participants rated the same sounds using a standard onedimensional annoyance measure. The results showed that both the one- and two-dimensional measures discriminated between reactions to different sounds. Regression analyses showed that the two-dimensional measure tapped aspects of human experience not covered by the annoyance measure. In addition, it was shown that only modifications of the fundamental frequency and the overall noise spectral level, but not modifications of harmonics, had a marked effect on emotional reactions. The implications of these findings for both auditory emotion research and noise control engineering are discussed.

Keywords: Academic Procrastination; Self-Regulation; Active Procrastination; Self-Handicapping

\section{Introduction}

For a long time researchers have studied human responses to exterior aircraft community noise (e.g. Berglund, Berglund, \& Lindvall; see Job 1988 for an overview). Some main findings from this research are that level and spectral characteristics such as presence of tonal components and tone-to-noise ratio are important determinants of subjective annoyance (Berglund \& Lindvall, 1995). Considerably fewer researches have reported on human responses to interior sounds (Powell \& Fields, 1995). The research reported on interior noise has mainly focused on the relation between overall dBA level and annoyance (Fastl \& Widman, 1990; Holmgren, 1999). Today, however, the loudness of the interior of an aircraft is often at acceptable levels. Therefore, other psychoacoustic attributes such as roughness, tone-to-noise ratio, and sharpness may contribute to the overall experienced sound quality (Zwicker \& Fastl, 1999). Sound quality optimization may therefore be an important tool to further improve passenger satisfaction.

In order to improve the interior sound environment various technical implementations can be made by the use of, for instance, active noise control (Emborg, Holmgren, Samuelsson, \& Leth, 1998) or structural improvements (Mixon \& Wilby, 1995). The modifications will mainly affect the presence of tonal

*Author note: This research was financially supported by a grant from the Swedish National Aviation Research Program NFFP and from the Swedish Research Council (VR).

\#Corresponding author. components, spectral balance and consequently the overall sound level. Following this, it is important to study how modifications of, for example, the fundamental frequency, influence subjective reactions. It may well be that even though improvements can be made they may have little effect on subjective reactions such as annoyance. The present research therefore focused on effects on influencing passenger reactions of modifications of 1) the tones (fundamental frequency, harmonics) 2) the noise spectra and 3) the tone and noise balance.

Apart from the overall finding that unpleasantness increases with increasing level (Todd, 2000; Vitz, 1973), previous researches have shown that the presence of a single tone in the noise spectra significantly increases annoyance ratings (Hellman, 1982; Holmberg, Landström, \& Kjellberg 1993; Landström, Kjellberg, Tearz, \& Åkerlund, 1995) and decreases human performance (Landström, Kjellberg, \& Söderberg, 1993). Further, annoyance is dependent on the relationship between the frequency of the tone and the spectral shape of the noise. For instance, a single tone added to a low-pass noise contributes more to overall annoyance (and loudness) than if the tone is added to a flat broadband or high-pass noise (Hellman, 1984; Kryter \& Pearsons, 1965). In addition, multiple tones further deteriorate comfort and increase annoyance (Hellman, 1985). Similar to these findings, research has shown that the more prominent a tone is the more annoying is the sound (Terhardt, 1982). In turboprop aircraft strong tonal components exist, due to the blade pass frequency (Kleiner, 1993; Mixon \& Wilby, 1995). Various measures can be taken to reduce the audibility of the 
fundamental frequency (corresponding to the blade pass frequency) and harmonics such as cabin sound insulation and active noise control (Emborg et al., 1998).

However, also the shape of the noise spectra influences annoyance ratings. Increasing level of broadband noise often results in increased annoyance (Berglund \& Lindvall, 1995; Berglund, Hassmén, \& Preis, 2002). Random or stochastic broadband excitation may be a result of airframe noise coming from the airflow around the fuselage, or may be caused by various air-intake systems and air conditioners. Noise spectral components in the high frequency area are also often subjectively perceived as sharp (Aures, 1985; Zwicker \& Fastl, 1999).

Tones and noise spectra are thus expected to influence annoyance reactions in similar ways. Reducing prominent tones should lead to decreased annoyance as should decreased overall noise spectra level. However, if one reduces the tone content of the spectrum, the noise component will be more salient. It may be asked how subjective ratings will be affected by such modifications.

Considering subjective reactions to sound as a multidimensional construct, as compared to a uni-dimensional pleasantnessunpleasantness or discrete annoyance view, might help resolve this apparent conflict. Traditionally, subjective affective or emotional reactions such as annoyance, disturbance, and irritation have been equated with a uni-dimensional positive-negative view (Maffiolo, Castellengo, \& Dubois, 1999; Vitz, 1973). However, a number of independent researchers have shown that at least two underlying dimensions may describe affective reactions to auditory stimuli. Bisping (1995, 1997), Bradley and Lang (2000) and Västfjäll, Kleiner and Gärling (2002; Västfjäll, Gulbol, Kleiner, \& Gärling, 2002; Västfjäll, 2012) found that two bipolar dimensions, activation-deactivation and pleasantness-unpleasantness, describe the affective reactions to the quality of natural and product sounds. The underlying idea is that affective reactions induced by auditory stimuli can be described by the combination of the two orthogonal dimensions valence and activation (Russell, 1980; Russell \& Barrett, 1999). Figure 1 displays the affective circumplex with the primary dimensions of activation and valence (Russell, 1980). According to this model, an affective reaction such as elation is the combination of pleasantness and high activation (upper right quadrant in Figure 1). An affective reaction such as calmness is similar in pleasantness, but low in activation (lower right quadrant). Boredom is the combination of unpleasantness and low activation (lower left quadrant) and distress is the combination of unpleasantness and high activation (upper left quadrant). The affective reaction annoyance would be positioned in the upper left quadrant of Figure 1. Note that annoyance, as it has been studied in most acoustic researches, stretches from not at all annoyed/neutral (the crossing point of the valence and activation axes) to very annoyed (along the circle of Figure 1).

In the domain of aircraft sound quality, we (Västfjäll, Kleiner, \& Gärling 2002; Väatfjäll et al., 2003) found that the dimensions of valence and activation discriminated between affective reactions to 20 aircraft sounds. In addition, the affective reactions were only weakly related to conventional sound quality metrics with the exception that valence reactions (positive/ negative reactions) were related to loudness. Psychoacoustical correlates to the affect dimensions were obtained in an experiment where participants rated perceptual properties of the sounds. Valence was highly correlated with perceived loudness

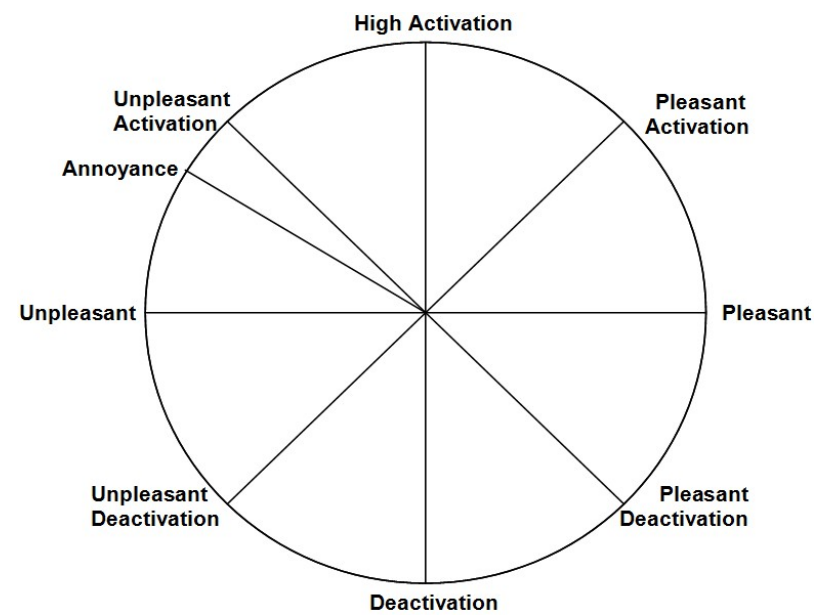

Figure 1.

The affect circumplex with the two main dimensions valence and activation.

$(-0.81)$, and the activation dimension was related to perceived sharpness $(0.58)$ and tonality $(-0.64)$. Thus, valence may be expected to primarily be related to loudness and tonality changes with more negative reactions with increasing sound level/tone. Activation ratings are expected to primarily be related to decreasing tone/increasing noise spectra. Taken together, a two-dimensional view of affective reactions to sound is expected to yield more information than merely asking participants about their annoyance reactions (Berglund \& Lindvall, 1995; Västfjäll et al., 2003).

Previous studies using the two-dimensional theory of affect have also found it useful to model how attractive participants think it is to feel in a certain way. Participants' preference or attractiveness ratings may provide further information on how the sound environment may be optimized. A sound environment that results in preferred reactions should also be optimal from a sound quality point of view.

The notion that people dislike certain affective states (unpleasant and low/high activation/powerfulness) and like others (pleasant and low/high activation/powerfulness) is implicit in the view that certain sounds produces more negative (annoyance) reactions than others. In the present research where subjective reactions are conceptualized in terms of two dimensions (valence and activation) rather than one (annoyance), it may be asked how preference is related to these dimensions? In studies of affect-eliciting qualities of visual environments, Russell and Mehrabian (1978) proposed that an approach tendency or preference is directly related to valence (their "pleasure-arousal hypothesis"). The relationship to activation was hypothesized to be inverted U-shaped for a preference maximum that increases with valence.

As may be seen in Figure 2, the pleasure-arousal hypothesis predicts that for affective states similar in unpleasantness, low and moderate activation, unpleasant states will be preferred, for valence-neutral affective states, medium activation will be preferred, and for high valence states, high activation will be preferred over medium and low activation. In short, for unpleasant states, people prefer to feel bored (low activation state) over distressed (high activation state). For pleasant states, people prefer to feel elated (high activation state) over calm (low activation state). 


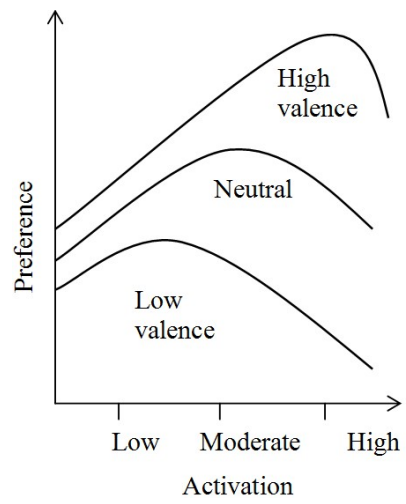

Figure 2.

The pleasure-arousal hypothesis.

Västjäll, Gulbol, Kleiner, and Gärling (2002) found in accordance with Figure 2, that preference ratings were related to both valence and activation of the affective reaction to the sound. Again, a two-dimensional view is expected to provide information about the users' subjective reactions and how to improve the interior acoustical quality. If sound modifications for instance will result changes in reactions in terms of lowered activation, but not valence, still a significant improvement (more attractive reaction) may have been achieved. A unidimensional valence view may not easily capture this.

\section{The Present Study}

The present study aimed at:

1) Examining how modifications of a tone or combination of tones (fundamental and/or harmonics) and level of noise spectra (noise-tone balance) influenced subjective reactions. It was hypothesized that tone manipulations mainly would affect valence and annoyance reactions. For noise spectra level, it was hypothesized that valence/annoyance would become more positive with decreasing level, whereas activation was expected to decrease with decreasing level (have its maximum at high noise spectra level) (hypothesis 1). These hypotheses were investigated by having participants rating modifications or synthesized versions of a binaural reference aircraft sound. These results are expected to give valuable information as to what and how large modifications to the sound environment that is needed to have a marked effect on subjective reactions.

2) The second aim was to pit a one-dimensional view on emotional reactions to sound (annoyance) against a two-dimensional view (valence and activation). This was done by having to separate samples of participants rating the same sounds either using valence and activation measures, or an annoyance measure. It was expected that annoyance ratings should be related to both the activation and valence dimensions (hypothesis 2).

3) A final aim was to validate the finding that preference ratings are related to both the valence and activation qualities of the reaction (Västfjäll et al., 2012) (hypothesis 3). This was enabled by having participants rating their preference for the sound concurrent with valence and activation ratings.

\section{Method}

\section{Participants}

Thirty-two undergraduates, 12 female and 20 males, volun- tarily participated in the experiment. Their mean age was 22.3 years (SD 2.12 range 19 - 30). All reported having normal hearing.

\section{Measures and Material}

Ratings scales. Valence and activation measures: The affect measures consisted of two bipolar scales each defined by three adjective pairs found in previous research to tap valence and activation, respectively (Västfjäll, Friman, Gärling, \& Kleiner, 2002). Sleepy-awake, dull-peppy, and passive-active were used to define the activation scale, displeased-pleased, sad-glad, and depressed-happy were used to define the valence scale. An additional scale was included to measure preference. This scale was defined by the adjectives attractive, likeable, and preferred over a neutral state. Beneath all three sets of adjective pairs appearing on a single page, numbers ranging from -4 over 0 to 4 were typed. Participants were requested to circle the number that corresponded to their feeling or preference.

Annoyance measure: The annoyance measure was a 9-point unipolar scale with verbal endpoints not at all (1) to very much (9).

Sound stimuli. A binaurally recorded sound from the interior of a SAAB 2000 Test Aircraft 003 was used a the base stimulus (plotted in Figure 3). From this sound a number of modified versions were created where the fundamental frequency and/or harmonics or the noise spectrum were changed. Figure 4 outlines a schematic representation of the modifications. The upper panel shows the original sound with fundamental, harmonics and noise spectrum. The middle panel illustrates modifications made to the fundamental frequency. From the original sound (reference sound 0), the fundamental frequency was increased or decreased in steps of $3 \mathrm{~dB}$. Together, four new sounds were created by changing the fundamental frequency in this way (see Table 1). Using the same methodology $F_{1}$ was modified in the same way (keeping $\mathrm{F}_{0}$ unmodified), resulting in four additional sounds (see Table 1). It was decided that mainly the fundamental and first harmonic should be modified since additional harmonics contributes little to the aural impression for this specific type of sound (Kleiner, 1993). Finally, the lower panel of Figure 4 illustrates how the noise spectra was increased or decreased (relative to the original sound) in steps of $3 \mathrm{~dB}$.

As may be seen in Table 1, various factorial combinations of $F_{0}$ and $F_{1}$ changes were also created. Including the original sound, the test battery contained 35 test sounds, divided into block of five sounds.

Apparatus. The stimuli were generated using digital signal processing software and were digitally stored on a computer. Stimulus presentation was made on computers using an experiment program. The sounds were delivered via Stax electrostatic headphones.

Procedure. Participants served individually or in groups of a maximum of three persons at a time. Upon arrival to the laboratory, they were first instructed how to use the scales and equipment. They were instructed that they would perform ratings of their reactions to various aircraft sounds. All participants listened to and rated each of the five sounds in each of the seven blocks. Presentation order of block and sounds within the blocks were counterbalanced over individuals. Participants were randomly assigned to annoyance ratings $(n=16,10$ males) or affect ratings $(\mathrm{n}=16,10$ males $)$. 


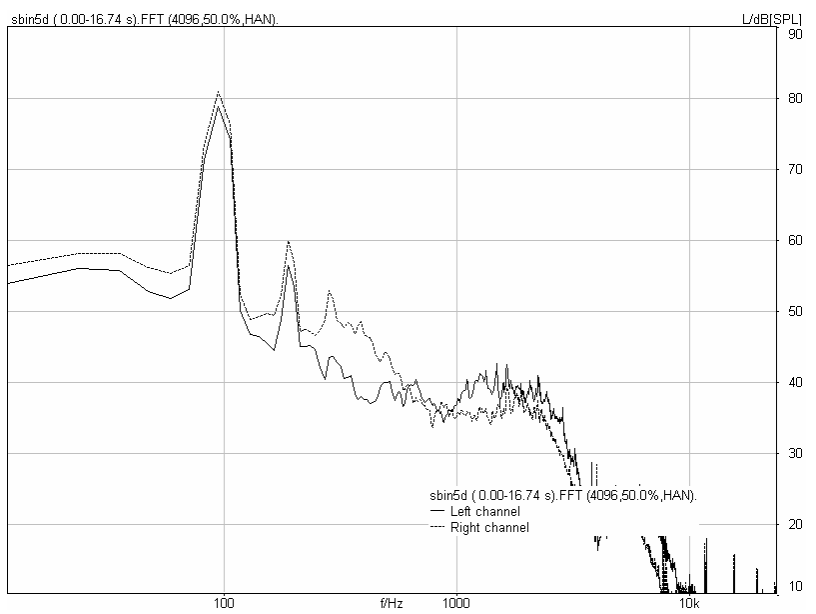

Figure 3.

FFT of the original base sound stimuli.
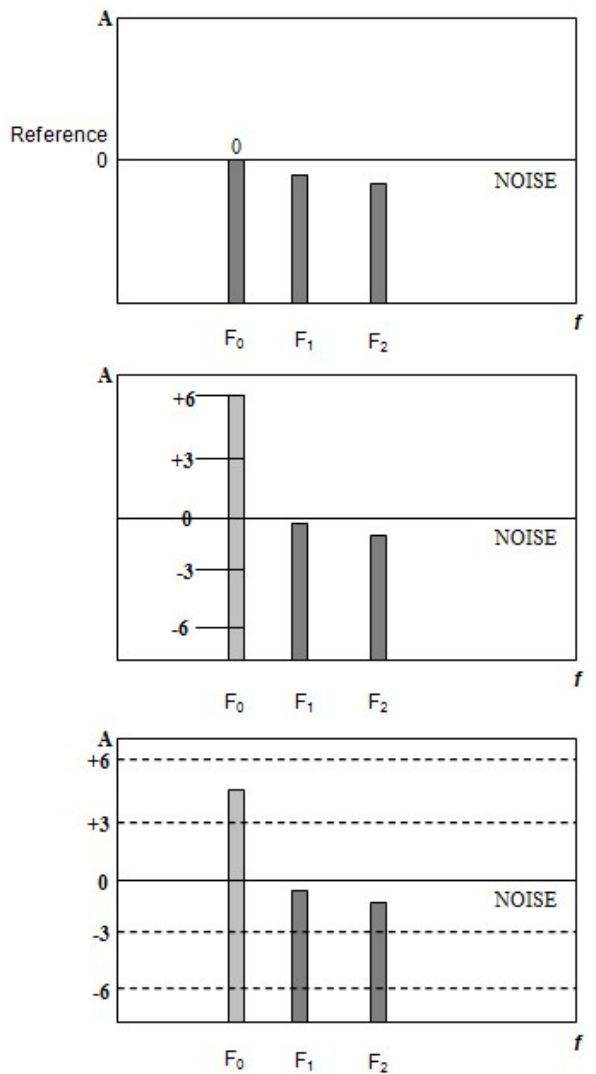

Figure 4.

A schematic overview of the modification scheme used to create the sound stimuli.

Participants first listened and rated five trial sounds (other than the test stimuli). After that they rated the five sounds in the first block, participants continued with remaining sound blocks. When participants had rated all the sounds, they were debriefed, compensated, and thanked for their participation.

\section{Results}

Overview of analysis strategies. Participants listened to blo-
Table 1.

Overview of test stimuli based on modification of the original sound.

\begin{tabular}{|c|c|c|c|}
\hline \multirow{2}{*}{$\begin{array}{c}\text { Stimuli block number and main } \\
\text { component(s) }\end{array}$} & \multicolumn{3}{|c|}{ Change in $\mathrm{dB}$ relative to reference sound } \\
\hline & F0 & F1 & Noise spectra \\
\hline \multirow[t]{5}{*}{ 1) Fundamental frequency } & Original & & \\
\hline & $+3 \mathrm{~dB}$ & & \\
\hline & $+6 \mathrm{~dB}$ & & \\
\hline & $-3 \mathrm{~dB}$ & & \\
\hline & $-6 \mathrm{~dB}$ & & \\
\hline \multirow[t]{5}{*}{ 2) Harmonic } & & Original & \\
\hline & & $+3 \mathrm{~dB}$ & \\
\hline & & $+6 \mathrm{~dB}$ & \\
\hline & & $-3 \mathrm{~dB}$ & \\
\hline & & $-6 \mathrm{~dB}$ & \\
\hline \multirow{5}{*}{ 3) Noise spectra } & & & Original \\
\hline & & & $+3 \mathrm{~dB}$ \\
\hline & & & $+6 \mathrm{~dB}$ \\
\hline & & & $-3 \mathrm{~dB}$ \\
\hline & & & $-6 \mathrm{~dB}$ \\
\hline \multirow[t]{6}{*}{ 4) Fundamental and Harmonic 1} & $+6 \mathrm{db}$ & & \\
\hline & $+6 \mathrm{db}$ & $+6 \mathrm{~dB}$ & \\
\hline & $+6 \mathrm{db}$ & $+3 \mathrm{~dB}$ & \\
\hline & $+6 \mathrm{db}$ & Original & \\
\hline & $+6 \mathrm{db}$ & $-3 \mathrm{~dB}$ & \\
\hline & $+6 \mathrm{db}$ & $-6 \mathrm{~dB}$ & \\
\hline \multirow[t]{5}{*}{ 5) Fundamental and Harmonic 2} & $+3 \mathrm{db}$ & $+6 \mathrm{~dB}$ & \\
\hline & $+3 \mathrm{db}$ & $+3 \mathrm{~dB}$ & \\
\hline & $+3 \mathrm{db}$ & Original & \\
\hline & $+3 \mathrm{db}$ & $-3 \mathrm{~dB}$ & \\
\hline & $+3 \mathrm{db}$ & $-6 \mathrm{~dB}$ & \\
\hline \multirow[t]{5}{*}{ 6) Fundamental and Harmonic 3} & $-3 \mathrm{db}$ & $+6 \mathrm{~dB}$ & \\
\hline & $-3 \mathrm{db}$ & $+3 \mathrm{~dB}$ & \\
\hline & $-3 \mathrm{db}$ & Original & \\
\hline & $-3 \mathrm{db}$ & $-3 \mathrm{~dB}$ & \\
\hline & $-3 \mathrm{db}$ & $-6 \mathrm{~dB}$ & \\
\hline \multirow[t]{5}{*}{ 7) Fundamental and Harmonic 4} & $-6 \mathrm{db}$ & $+6 \mathrm{~dB}$ & \\
\hline & $-6 \mathrm{db}$ & $+3 \mathrm{~dB}$ & \\
\hline & $-6 \mathrm{db}$ & Original & \\
\hline & $-6 \mathrm{db}$ & $-3 \mathrm{~dB}$ & \\
\hline & $-6 \mathrm{db}$ & $-6 \mathrm{~dB}$ & \\
\hline
\end{tabular}

cks of five sounds (for each modification) and within-group analysis of variance (ANOVA) were used to evaluate differences within each block. To correct for possible violations of sphericity, Grenhousse-Geisser correction of the degrees of freedom was used. To evaluate the relationship between annoyance and affect ratings, Pearson correlation coefficients and regression analyses were applied. The annoyance ratings were converted from a 1 to 9 point scale to a -4 to 4 scale to facilitate comparisons with the affect scales.

\section{Emotional Reactions to Sound Modifications}

Fundamental Frequency: The within-subjects ANOVAs for the modifications of the fundamental frequency (modification 
block 1) was significant for the valence, $\mathrm{F}(2.48,37.61)=9.01$, $p<0.001$, activation, $\mathrm{F}(3.24,48.70)=3.05, p<0.02$, and preference scales, $\mathrm{F}(2.65,39.83)=10.68, p<0.001$. Figure 5 displays the mean ratings for the valence, activation, and preference scales. Bonferroni-corrected contrast tests at $p=0.05$ showed that for the valence and preference scales all mean comparisons, with the exceptions of -3 and $-6 \mathrm{db}$ and the 0 and -3 comparisons, were significant. For the activation scale only the comparison between the original and $-6 \mathrm{~dB}$ was significant.

The ANOVA for the annoyance ratings was significant, $\mathrm{F}(2.99,44.94)=11.79 . p<0.001$. Bonferroni-corrected contrasts showed that all comparisons were significant except that of -3 and $-6 \mathrm{~dB}$.

Harmonic: The analysis for harmonic modifications (modification block 2) showed that there were no significant overall effects on either the valence, $\mathrm{F}(1.94,29.12)=0.11$, ns., activation, $\mathrm{F}(1.96,29.47)=0.19$, ns., preference, $\mathrm{F}(1.98,29.81)=$ 0.55 , ns., or annoyance $\mathrm{F}(2.12,42.15)=1.09$, ns.

Noise spectra: The within-subjects ANOVAs for the modifications of the harmonic (modification block 3) was significant for the valence, $\mathrm{F}(2.86,42.96)=12.51, p<0.001$. Bonferronicorrected contrast tests showed that only the differences between $+6 \mathrm{~dB}$ and all other levels were significant (Figure 6). The ANOVA for activation was also significant, $F(2.99,44.97)$ $=23.89, p<0.001$, and the contrast showed that $+6 \mathrm{~dB}$ modification resulted in significant higher levels of activation than all other sounds. Also the $+3 \mathrm{~dB}$ modification induced significantly higher levels of activation than did the -3 , and $-6 \mathrm{~dB}$ excerpts. The ANOVA for preference scale was significant, $\mathrm{F}(2.50,37.58)=23.37, p<0.001$. Again, the contrasts showed that $+6 \mathrm{~dB}$ modification was significantly less preferred compared to the other sounds. Also the $+3 \mathrm{~dB}$ modification was rated as less liked than the -3 and $-6 \mathrm{~dB}$ excerpts.

The ANOVA for the group performing annoyance ratings also yielded a significant main effect, $\mathrm{F}(2.87,43.07)=22.22, p$ $<0.001$. The contrasts showed that $+6 \mathrm{~dB}$ modification was significantly more annoying compared to the other sounds. Also the $+3 \mathrm{~dB}$ modification was more annoying than the -3 , and $-6 \mathrm{~dB}$ excerpts.

Combined noise and harmonic modifications. Separate

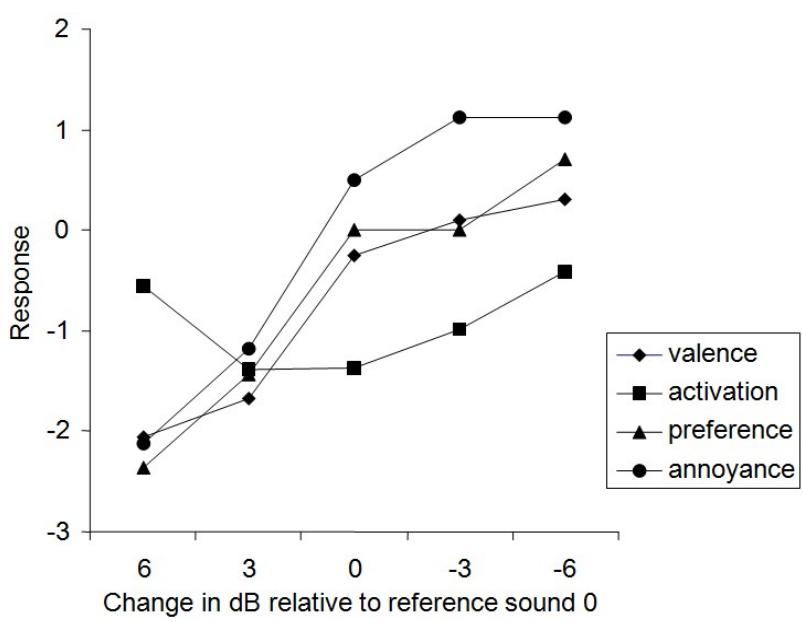

Figure 5.

Mean ratings of valence, activation, preference, and annoyance for fundamental frequency modifications (block 1).

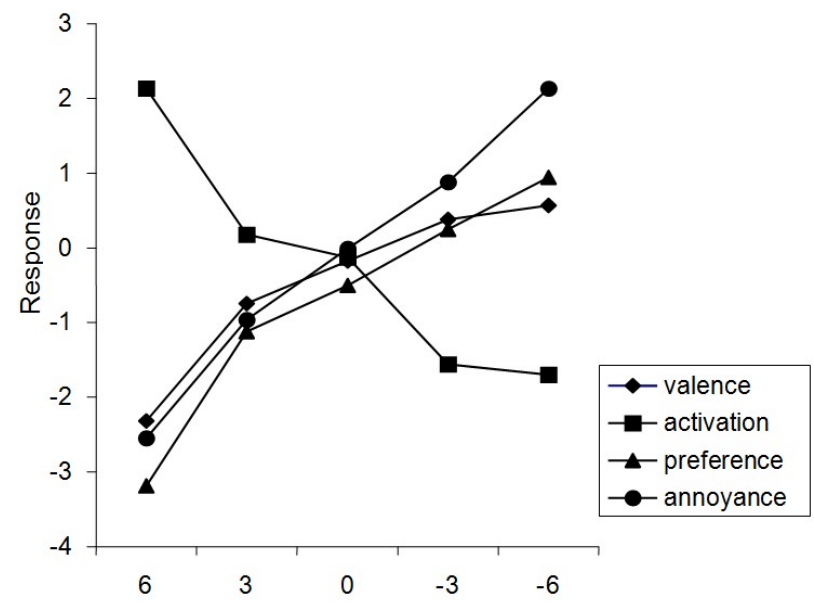

Change in $\mathrm{dB}$ relative to reference sound 0

\section{Figure 6.}

Mean ratings of valence, activation, preference, and annoyance for noise spectral modifications (block 3).

ANOVAs were performed for and of the fundamental and harmonic blocks (modifications block 4, 5, 6, and 7 in Table 1). No significant effects were obtained on valence, activation, preference, or annoyance scales.

\section{Preference, Valence, and Activation}

To test the hypothesis that preference ratings are related to both valence and activation qualities of the sound, separate regression analyses was performed for the conditions where significant variation was observed: fundamental frequency and noise spectra. The dependent variable was participants' preference ratings, and independent variables were the valence and activation ratings. The pleasure-arousal hypothesis also suggest that a quadratic component of activation $\left(\mathrm{A}^{2}\right)$ and a valence by activation interaction $(\mathrm{V} \times \mathrm{A})$ should be related to preference. Therefore, two additional variables corresponding to these components were tested in the regression analyses (substituting linear activation). Observations were pooled over individuals and sounds thus resulting in 80 observations (16 participants $\times$ five sounds). Over all observations valence and activation correlated 0.26 (ns) for the fundamental frequency ratings, and -0.31 (ns) for the noise spectra ratings. Table 2 reports the regression analyses. As may be seen, for both analyses the independent variables were significantly related to preference. For the fundamental frequency ratings, the model with linear valence and activation showed that activation was not significantly related to preference ratings. However, for the second model the quadratic activation and the valence by activation interaction were significant. In addition, the explained variance increased from 0.58 to 0.64 . Similar results were obtained for the noise spectra ratings. However, in this analysis also the linear activation was significant. This difference is most probably due to the increased variation in activation ratings for the noise spectra modifications as compared to the fundamental frequency modifications (see Figures 5 and 6).

\section{Annoyance versus Affect Ratings}

To test the hypothesis that annoyance ratings are related to activation, valence, and preference ratings, all observations 
Table 2.

Regression analyses of the relationship between participants' preference and valence/activation ratings.

\begin{tabular}{cccc}
\hline Model $^{\mathrm{a}}$ & $\mathrm{F}$ & $\mathrm{df}$ & $\mathrm{R}_{\text {adj }}^{2}$ \\
\hline \multicolumn{5}{c}{ Fundamental frequency modification ratings } \\
$\mathrm{P}=$ Valence $_{0.79^{* *}}-$ Activation $_{0.11}$ & $55.49^{* *}$ & 2,77 & $0.58^{* *}$ \\
$\mathrm{P}=$ Valence $_{0.77^{* *}}-\mathrm{A}_{0.15^{*}}^{2} \mathrm{~V} \times \mathrm{A}_{0.13^{*}}$ & 43.45 & 3,76 & $0.63^{* *}$ \\
Noise spectra modification ratings \\
$\mathrm{P}=$ Valence $_{0.67^{* *}}-$ Activation $_{0.19^{*}}$ & $57.96^{* *}$ & 2,77 & $0.54^{* *}$ \\
$\mathrm{P}=$ Valence $_{0.66^{* *}}-\mathrm{A}_{0.18^{*}}^{2}+\mathrm{V} \times \mathrm{A}_{0.19^{*}}$ & $28.33^{* *}$ & 3,76 & $0.62^{* *}$ \\
\hline
\end{tabular}

${ }^{\text {a }} \mathrm{P}=$ preference, $\mathrm{A}^{2}=$ quadratic activation, $\mathrm{V} \times \mathrm{A}=$ valence by activation interaction. ${ }^{*} p<0.05 ;{ }^{* *} p<0.01$.

were pooled over individuals and sounds yielding 80 observations for fundamental frequency and noise spectra modifications, respectively. Following this regression analyses were performed with the annoyance ratings as dependent variable, and the valence, activation, and preference ratings as independent variables. For ratings of fundamental frequency it was found that annoyance ratings correlated 0.13 (ns) with valence, -0.19 (ns) with activation, and $0.27(p<0.01)$ with preference. The regression analysis was significant, $\mathrm{F}(3,76)=3.57, p<$ $0.01, \mathrm{R}^{2}{ }_{\mathrm{adj}}=0.10$. The beta weights for preference $(0.36)$ and activation $(-0.21)$ were significant at $p=0.05$, whereas the beta weight for valence was non-significant $(-0.09)$.

The analysis of noise spectra modifications showed than annoyance ratings correlated $0.41(p<0.001)$ with valence, -0.62 $(p<0.001)$ with activation, and $0.49(p<0.001)$ with preference. Consequently, the regression analysis was significant, $\mathrm{F}$ $(3,76)=21.85, p<0.001, \mathrm{R}^{2}{ }_{\text {dj }}=0.44$ with significant standardized beta weights for activation $(-0.51)$ and preference $(0.22)$, but not valence $(0.10)$.

\section{Discussion}

The present research set out to study how different tonal and noise modifications influence emotional reactions. In line with previous findings (Västfjäll et al., 2002), support was found for the idea that valence/annoyance reactions should mainly be affected by tonal components and the activation dimension by noise spectra modifications (hypothesis 1). Significant variations in valence, activation and annoyance ratings were found for the fundamental frequency modifications (block 1) and noise spectral modifications (block 2). However, modifications of the first harmonic (holding fundamental and noise spectra constant) did not significantly affect subjective reactions.

Clearly, the modifications made in the present study not only affected the perceived tonal or noise balance, but also resulted in loudness variations. However, loudness alone cannot explain why different modifications have different effects on subjective reactions. To recapitulate, it was found that participants experienced an increased state of activation and increasingly negative feelings as the noise component (and loudness) increased (noise modifications block 2). However, in another condition where the tone components (and loudness) were varied, participants experienced an increased negative, unpleasant feeling, but the effect on activation was minor (fundamental modifications block 1). Both types of modifications resulted in loudness increases or decreases, but they had different effects on experience measured by the two dimensions valence and activation. Thus, it appears that modifications affecting the noise spectra or noise spectral balance is related to the activation dimension of experience, whereas tonal modifications are related to pleasantness-unpleasantness component of subjective experience.

These findings suggest that even though improvements can be made by canceling out the fundamental frequency or lower the overall noise level, other modifications of for instance the balance between fundamental and harmonic may have little effect on subjective reactions. The finding that valence and activation were differently affected by the same modification also has effects on decisions of how to optimize the sound environment. If one desires to minimize the activation component of the experience, modifications of overall noise spectra level may be sought. If the goal instead is to minimize unpleasant reactions, tone modifications may be the primary aim. In order to understand the relevance of this difference it is important to review some recent research suggesting that valence and activation have different effects on behavior, performance, and physiology (Russell \& Barrett, 1999). It is well known that a noisy environment may induce stress (a combination of high activation and unpleasantness) or that listening to music may result in a feeling of euphoria with accompanying psychophysiological responses and impact on cognitive functions (Evans, Hygge, \& Bullinger, 1995). More specifically, valence is associated with changes in heart rate and facial micromovements, whereas activation is related to electrodermal responses (Lang, 1995). For cognitive abilities, performance, information processing, and problem solving, valence is associated with mood-congruent judgments, whereas activation is related to constraints on information processing capabilities and arousal-congruent judgments (Clark, Millberg, \& Erber, 1984).

According to the affective circumplex, any affective reaction should be possible to characterize in terms of its position along the valence and activation axes (Russell \& Barrett, 1999). Hypothesis 2 explored the possibility that annoyance reactions are combinations of valence and activation. In two separate regression analyses it was shown that annoyance ratings were systematically related to preference and activation ratings, but not to valence. Moreover, these two variables could only account for modest percentage of the variance in annoyance ratings (10\% and $44 \%)$. The relatively low overlap can in part be due to the fact that a between-subjects design was used; participants either rated the sounds using an annoyance scale or valence/ activation/preference scales. The fact that preference, rather than valence was related may be due to the high intercorrelation between them, resulting in that only one of the two variables was retained in the regression analyses. However, it was still expected that a larger percentage of the variance in annoyance should have been accounted for by the independent variables. Thus, only partial support for hypothesis 2 was obtained in that both preference/valence and activation were systematically related to activation. However, counter to hypothesis 2 , the annoyance scale measures aspects not fully covered by the valence and activation dimensions. An aspect differentiating annoyance from valence-activation is that annoyance concerns a feeling state caused by a sound and effects on behavior or performance (annoyed/disturbed when doing $\mathrm{x}$ ), whereas valence and activation are pure "core" feelings (Berglund \& Lindvall, 1995; Russell \& Barrett, 1999; Västfjäll et al., 2002). Another way to understand the difference between core affects and annoyance is the notion that annoyance is a discrete affective state with associated appraisal patterns (Russell \& Barett, 
1999). Appraisals refer to a cognitive assessment of antecedent conditions (this sound is loud and it is disturbing me when I need to concentrate). Core affects on the other hand are unappraised (with no object) feelings. Consequently, a component of annoyance may be core affects (valence and activation) but the full-blown experience of annoyance/disturbance is likely to involve cognitive appraisal components. Thus, valence and activation may only in part capture annoying experiences. Given that measuring core affects and discrete reactions (such as annoyance) have different advantages where valence-activation are related to information processing and physiology, and annoyance to activity disturbance and performance, it may be concluded that both measures should be used to fully understand emotional reactions to sound. However, the present research goes beyond most research on sound quality optimization by showing that reactions should be measured by, at least two dimensions, and that these dimensions taps into aspects of noise perception not covered by annoyance measures. Most importantly, the two-dimensional valence/activation model offered here also allows for positive hedonic experience (it is a pleasant sound), an important aspect of sound quality.

In addition, the present research suggests that a measure of emotional reactions to sounds should also include a measure of liking for the sound (see also Berglund et al., 2002, for the discussion of affective processes and preferences). In contrast to many studies of human response to sound, we argue that liking for a sound cannot be equated with pleasantness. Instead, both valence and activation of the reaction should be related to sound preference. In support of this hypothesis, regression analyses showed that preference was related to valence and activation as predicted by the pleasure-arousal hypothesis (Russell \& Mehrabian, 1978). A similar conclusion was previously reached by Västfäll et al. (2012) for recordings or real interior environmental sounds.

To summarize, at a theoretical level, the present research has gone beyond exiting research in showing that a well established model for emotional reactions based on the two dimensions of valence and activation describe emotional reactions to various sounds (see also Bergman et al., 2009; Tajadura et al., 2010a; $2010 \mathrm{~b}$ for similar results). Together with the findings suggesting that this model can account for and discriminate between subjective reactions to a number of different sound sources such as product sounds (Bisping, 1997; Västfjäll et al., 2012), tones (Asutay \& Västfjäll, 2012), various environmental sounds (Björk, 1985), everyday sounds and human voices (Bradley \& Lang, 2000) and music (Juslin \& Västfjäll, 2008), it should now be considered as a alternative or complementary measure to standard noise annoyance measures. In addition, a valence/ activation measure may provide insights into aspects of perception and physiology not easily covered by one-dimensional measures. A measure combining standard verbal report measures of subjective noise reactions with the valence/activation measure will most likely have a higher explanatory power than either alone (västfjäll \& Gärling, 2007). The valence/activation measure is to date available in many different languages (Russell, 1980; see Västfjäll et al., 2002 for an overview) and various non-verbal graphical scales for use in different populations have been developed (Lang, 1995; Russell, Weiss, \& Mendelsohn, 1989). From a sound quality optimization viewpoint, the valence and activation measure may be combined with the preference measure to predict user responses to various sound modifications.
At a practical level, the present results showed that not all possible modifications have a marked effect on human reactions, even though such modification may be measurable, visible in graphical depictions of the sound, or even audible (Quehl et al., 2000). The present study demonstrated that mainly overall noise level, the fundamental frequency, and the balance between the two, had a significant effect on self-reported reactions. Modification of the first harmonic and the relative balance between the fundamental and the harmonic had little effects. Even though this study is limited to one type of turboprop sound and future investigations needs to extend these findings to other sounds, it still suggest that certain modifications may be more important and have more impact than others. The present study introduced an alternative approach to the measurement of human reaction to sound modifications that may be used in future research and applications.

\section{REFERENCES}

Asutay, E., \& Västfjäll, D. (2012). Perception of loudness is influenced by emotion. PLOS ONE, 7, e38660. http://dx.doi.org/10.1371/journal.pone. 0038660

Aures, W. (1985c). Ein berechnungsverfahren für den sensorischen wohlklang beliebigen schallsignale. Acustica, 59, 130-141.

Bergman, P., Sköld, A., Västfjäll, D., \& Fransson, N. (2009). Perceptual and emotional categorization of sound. Journal of the American Acoustical Society, 126, 3156-3167.

http://dx.doi.org/10.1121/1.3243297

Berglund, B., \& Lindvall, T. (1995). Community noise. Stockholm: Center for Sensory Research.

Berglund, B., Berglund, U., \& Lindvall, T. (1975). Scaling loudness, noisiness, and annoyance of aircraft noise. Journal of the Acoustical Society of America, 57, 930-934. http://dx.doi.org/10.1121/1.380535

Berglund, B., Hassmén, P., \& Preis, A. (2002). Annoyance and spectral contrast are cues for similarity and preference of sounds. Journal of Sound and Vibration, 250, 53-64. http://dx.doi.org/10.1006/jsvi.2001.3889

Bisping, R. (1995). Emotional effect of car interior sounds: Pleasantness and power and their relation to acoustic key features (pp. 1203-1209). SAE Paper 951284, Warrendale, PA: SAE International.

Bisping, R. (1997). Car interior sound quality: Experimental analysis by synthesis. Acta Acustica, 83, 813-818.

Bradley, M. M., \& Lang, P. J. (2000). Affective reactions to acoustic stimuli. Psychophysiology, 37, 204-215. http://dx.doi.org/10.1111/1469-8986.3720204

Clark, M. S., Millberg, S., \& Erber, R. (1984). Effects on arousal on judgments of others' emotions. Journal of Personality and Social Psychology, 46, 551-560. http://dx.doi.org/10.1037/0022-3514.46.3.551

Emborg, U., Holmgren, J., Samuelsson, F., \& Leth, S. (1998). Active and passive noise control in practice on the Saab 2000 high speed turboprop. American Institute of Aeronautics and Astronautics paper 98-2231, American Institute of Aeronautics and Astronautics, Inc.

Evans, G. W., Hygge, S., \& Bullinger, M. (1995). Chronic noise and psychological stress. Psychological Science, 6, 333-338. http://dx.doi.org/10.1111/j.1467-9280.1995.tb00522.x

Fastl, H., \& Widman, U. (1990). Subjective and physical evaluation of aircraft noise. Noise Control Engineering Journal, 35, 61-63. http://dx.doi.org/10.3397/1.2827769

Job, R. F. S. (1988). Community response to noise: A review of factors influencing the relationship between noise exposure and reaction. Journal of the Acoustical Society of America, 83, 991-1001. http://dx.doi.org/10.1121/1.396524

Juslin, P. N., \& Västfjäll, D. (2008). Emotional responses to music: The need to consider underlying mechanisms. Behavioral and Brain Sciences, 31, 559-575.

Hellman, R. P. (1982). Loudness, annoyance, and noisiness produced by single-tone-to-noise complexes. Journal of the Acoustical Society 


\section{VÄSTFJÄLL}

of America, 72, 62-73. http://dx.doi.org/10.1121/1.388025

Hellman, R. P. (1984). Growth rate of loudness, annoyance, and noisiness as a function of tone location within the noise spectrum. Journal of the Acoustical Society of America, 75, 209-218.

http://dx.doi.org/10.1121/1.390397

Hellman, R. P. (1985). Perceived magnitude of two-tone complexes: Loudness, annoyance, and noisiness. Journal of the Acoustical Society of America, 77, 1479-1504. http://dx.doi.org/10.1121/1.392044

Holmberg, K., Landström, U., \& Kjellberg, A. (1993). Effects of ventilation noise due to frequency characteristics and sound level. Journal of Low Frequency Noise and Vibration, 12, 115-122.

Holmgren, J. (1999). Saab's experience in aircraft interior noise and vibration measurements. American Institute of Aeronautics and Astronautics paper 99-1837, American Institute of Aeronautics and Astronautics, Inc.

Kleiner, M. (1993). A pilot study of comfort criteria and sound quality metrics for sound inside cabins of propeller-driven aircraft. Report F93-03, Gothenburg: Chalmers University of Technology.

Kryter, K. D., \& Pearson, K. S. (1965). Judged noisiness of a band of random noise containing an audible pure tone. Journal of the Acoustical Society of America, 38, 106-112.

http://dx.doi.org/10.1121/1.1909578

Landström, U., Kjellberg, A., \& Byström, M. (1993). Acceptable levels of sounds with different spectral characteristics during the performance of a simple and a complex non-auditory task. Journal of Sound and Vibration, 160, 533-542. http://dx.doi.org/10.1006/jsvi.1993.1043

Landström, U., Kjellberg, A., Tesarz, M., \& Åkerlund, E. (1995). Exposure levels, tonal components, and noise annoyance in working environments. Environment International, 21, 265-275. http://dx.doi.org/10.1016/0160-4120(95)00017-F

Lang, P. J. (1995). The emotion probe: Studies of motivation and attention. American Psychologist, 50, 372-385. http://dx.doi.org/10.1037/0003-066X.50.5.372

Maffiolo, V., Castellango, M., \& Dubois, D. (1999). Is pleasantness for soundscapes dimensional or categorical? In Proceedings of the Forum Acusticum 1999, Berlin, CD-ROM.

Mixon, J. S., \& Wilby, J. F. (1995). Interior noise. In H. H. Hubbard (Ed.), Aeroacoustics of flight vehicles. Volume 2: Noise control (pp. 271-348). USA: Acoustical Society of America.

Pearsons, K. S., Bishop, D. E., \& Horonjeff, R. D. (1969). Judged noisiness of modulated and multiple tones in broad-band noise. Journal of the Acoustical Society of America, 45, 742-750. http://dx.doi.org/10.1121/1.1911455

Powell, C. A., \& Fields, J. M. (1995). Human response to aircraft noise. In H. H. Hubbard (Ed.), Aeroacoustics of flight vehicles. Volume 2: Noise control (pp. 1-48). USA: Acoustical Society of America.

Quehl, J., Schick, A., Mellert, V., Shulte-Fortkamp, B., \& Remmers, H. (2000). Evaluation of combined aircraft interior sound and vibration effects on passengers' well-being and comfort sensation: The elaboration of a concept-specific methodological instrument. In A. Schick, M. Meis, \& C. Reckhardt (Eds.), Contributions to psychological acoustics: Results of the eighth Oldenburg symposium on psychological acoustics. Oldenburg: Biblotheks- und Informationssystem der Universität Oldenburg.
Russell, J. A. (1980). The circumplex model of affect. Journal of Personality and Social Psychology, 39, 1161-1178. http://dx.doi.org/10.1037/h0077714

Russell, J. A., \& Mehrabian, A. (1978). Approach-avoidance and affiliation as functions of the emotion-eliciting quality of an environment. Environment and Behavior, 10, 355-387. http://dx.doi.org/10.1177/0013916578103005

Russell, J. A., \& Barrett, L. F. (1999). Core affect, prototypical episodes, and other things called emotion: Dissecting the elephant. Journal of Personality and Social Psychology, 76, 805-819. http://dx.doi.org/10.1037/0022-3514.76.5.805

Russell, J. A., Weiss, A., \& Mendelsohn, G. A. (1989). Affect grid: A single item scale of pleasure and activation. Journal of Personality and Social Psychology, 57, 493-502.

http://dx.doi.org/10.1037/0022-3514.57.3.493

Tajadura-Jimenez, A., Väljamäe, A., Asutay, E., \& Västfjäll, D. (2010). Embodied auditory perception: The emotional Impact of approaching and receding sound sources. Emotion, 10, 216-229. http://dx.doi.org/10.1037/a0018422

Tajadura-Jimenez, A., Larsson, P., Väljamäe, A., Västfjäll, D. \& Kleiner, M. (2010). When room size matters: Acoustic influences on emotional response to sounds. Emotion, 10, 416-422. http://dx.doi.org/10.1037/a0018423

Terhardt, E. F. (1982). Algorithm for extraction of pitch and pitch Salience from complex tonal signals. Journal of the Acoustical Society of America, 71, 697-688. http://dx.doi.org/10.1121/1.387544

Todd, N. (2001). Evidence for a behavioral significance of saccular acoustic sensitivity in humans. Journal of the Acoustical Society of America, 110, 380-390. http://dx.doi.org/10.1121/1.1373662

Vitz, P. C. (1973). Preference for tones as a function of frequency and intensity. Perception and Psychophysics, 11, 84-88. http://dx.doi.org/10.3758/BF03212689

Västfjäll, D., \& Kleiner, M. (1998). Sound quality: Do we base our decisions on emotions? In U. Kernen (Ed.), Proceedings of Nordic Acoustical Meeting 98 (pp. 221-226). Stockholm: Högskoletryckeriet.

Västfjäll, D. (2012). Emotional reactions to sound without meaning. Psychology, 3, 606-609. http://dx.doi.org/10.4236/psych.2012.38091

Västfjäll, D., Kleiner, M., \& Gärling, T. (2003). Affective reactions to interior aircraft sound quality. Acta Acustica, 89, 693-701.

Västfjäll, D., Friman, M., Gärling, T., \& Kleiner, M. (2002). The measurement of core affect: A Swedish self-report measure. Scandinavian Journal of Psychology, 43, 19-32. http://dx.doi.org/10.1111/1467-9450.00265

Västfjäll, D., \& Gärling, T. (2007). Validation of short self-report measure of core affect. Scandinavian Journal of Psychology, 48, 233-238. http://dx.doi.org/10.1111/j.1467-9450.2007.00595.x

Västfjäll, D., Gulbol, M.-A., Kleiner, M., \& Gärling, T. (2002). Affective evaluations of and reactions to exterior and interior vehicle auditory quality. Journal of Sound and Vibration, 255, 501-518. http://dx.doi.org/10.1006/jsvi.2001.4166

Zwicker, E., \& Fastl, H. (1999). Psychoacoustics: Facts and models (2nd ed.). Heidelberg: Springer-Verlag. http://dx.doi.org/10.1007/978-3-662-09562-1 